\section{Evaluation of a framework for safe and appropriate prescribing of psychoactive medications in a UK prison} \\ Bebbington, Emily; Lawson, Justin ; Nafees, Sadia; Robinson, Catherine; Poole, \\ Rob

\section{Criminal Behaviour and Mental Health} \\ DOI: \\ https://doi.org/10.1002/cbm.2187 \\ Published: 01/04/2021 \\ Peer reviewed version \\ Cyswllt i'r cyhoeddiad / Link to publication
}

Dyfyniad o'r fersiwn a gyhoeddwyd / Citation for published version (APA):

Bebbington, E., Lawson, J., Nafees, S., Robinson, C., \& Poole, R. (2021). Evaluation of a framework for safe and appropriate prescribing of psychoactive medications in a UK prison. Criminal Behaviour and Mental Health, 31(2), 131-142. https://doi.org/10.1002/cbm.2187

\footnotetext{
Hawliau Cyffredinol / General rights

Copyright and moral rights for the publications made accessible in the public portal are retained by the authors and/or other copyright owners and it is a condition of accessing publications that users recognise and abide by the legal requirements associated with these rights.

- Users may download and print one copy of any publication from the public portal for the purpose of private study or research.

- You may not further distribute the material or use it for any profit-making activity or commercial gain

- You may freely distribute the URL identifying the publication in the public portal?
}

Take down policy

If you believe that this document breaches copyright please contact us providing details, and we will remove access to the work immediately and investigate your claim. 
Evaluation of a framework for safe and appropriate prescribing of psychoactive medications in a UK prison

Running title: Psychoactive drug optimisation in prison

Dr Emily Bebbington (corresponding author) (ORCiD iD 0000-0003-1332-7558)

Welsh Clinical Academic Training Fellow in Emergency Medicine

Centre for Mental Health and Society, Bangor University, Wrexham Technology Park, Croesnewydd Road, Wrexham, Wales, LL13 7YP

Correspondence to: e.bebbington@bangor.ac.uk

Dr Justin Lawson (ORCiD iD 0000-0003-1368-6411)

General Practitioner

HMP Berwyn, Wrexham Industrial Estate, Bridge Rd N, Wrexham, Wales, LL13 9QE

Dr Sadia Nafees (ORCiD iD 0000-0003-1553-3013)

Research Officer

Centre for Mental Health and Society, Bangor University, Wrexham Technology Park, Croesnewydd Road, Wrexham, Wales, LL13 7YP

Professor Catherine Robinson (ORCiD iD 0000-0001-7240-7107)

Professor of Social Care Research

School of Health Sciences, 4th Floor Ellen Wilkinson Building, University of Manchester, Oxford Road, Manchester, England, M13 9PL

Professor Rob Poole (ORCiD iD 0000-0002-7914-3981)

Professor of Social Psychiatry

Centre for Mental Health and Society, Bangor University, Wrexham Technology Park, Croesnewydd Road, Wrexham, Wales, LL13 7YP 
Conflict of interest statement: All authors have completed the ICMJE uniform disclosure form at www.icmje.org/coi_disclosure.pdf and declare: EB, SN, CR, and RP had financial support from Betsi Cadwaladr University Health Board during the conduct of the study; $\mathrm{JL}$ is the Medical Director of Gables Medical (Offender Health) Ltd which is contracted to provide primary care services to HMP Berwyn.

Data availability statement: No additional data available.

Acknowledgements: We thank Betsi Cadwaladr University Health Board for funding this study. We are grateful for Dr Lynne Grundy's support. We are grateful to the pharmacy team at HMP Berwyn for helping to initiate and administer the medicines optimisation framework. Thank you to the two anonymous reviewers for their helpful comments on the earlier draft of this paper.

Funding: Betsi Cadwaladr University Health Board (BCUHB) provided funding for the study. BCUHB did not have any role in study design, data collection, data analysis, data interpretation, writing of the manuscript, nor decision to submit for publication.

Contributors: All authors critically reviewed earlier versions and approved the final manuscript. JL, CR, and RP conceived the paper. JL and SN developed the protocol for data collection. JL completed data collection. EB completed data cleaning. EB and JL developed the analysis plan. EB did the analysis and wrote the initial draft. All authors had access to all data in the study and can take responsibility for the integrity of the data and accuracy of data analysis. The corresponding author attests that all listed authors meet authorship criteria and that no others meeting the criteria have been omitted. 


\section{Abstract}

Background: The widespread use of drugs in prisons leads to avoidable deaths, poorer health and a poor living environment. The contribution of psychoactive prescription drugs to this problem has received little attention in prison policy and at individual prescriber level.

Aims: To determine the extent of unsafe and inappropriate prescribing of psychoactive medications in one UK prison using a newly developed medicines optimisation framework.

Method: A medicines optimisation framework was developed based on principles of good prescribing. It was initiated on the opening of a new prison - HMP Berwyn - in February 2017. During the study period, all prisoners at HMP Berwyn were transferred from other prisons. The safety and appropriateness of psychoactive medications were evaluated de novo on reception at HMP Berwyn and during follow up, using the medicines optimisation framework.

Results: 1941 sentenced men arrived at HMP Berwyn between February 2017 and November 2018. Nearly one-third (634, 33\%) were on a prescribed psychoactive medication. Seventyfive percent of these (474/634) required a prescription change due to appropriateness or safety concerns. Nearly half $(295,46.5 \%)$ received changes at reception despite having already undergone medicines reconciliation at their previous prison. Forty-three percent (275/634) received changes at follow up, most commonly those who had no prior risks identified at reception.

Conclusions Inappropriate and unsafe prescribing of psychoactive medications is occurring in prisons despite mandatory medication reviews. Ongoing monitoring is required to reduce the risk from these medications. A medicines optimisation framework such as this could be adopted across other prisons, worldwide, to help contribute to risk reduction from drug use in prisons. Appropriately modified, a similar framework might help reduce inappropriate and harmful prescribing in hospitals and in the community.

Keywords Prison; psychoactive substance; opioids; prescribing; medicines management 


\section{Introduction}

Drug use has been described as the "biggest single destabilising factor" in prisons in England and Wales by Her Majesty's Prison and Probation Service (HM Prison and Probation Service, 2018), directly contributing to adverse prisoner experiences and deaths. HMPPS Prisons' Drugs Strategy emphasises that tackling this problem requires a co-ordinated effort to restrict supply, reduce demand, and build recovery (HM Prison and Probation Service, 2019). Publicity and funding focuses on restricting supply of drugs through illicit routes using enforcement strategies including random mandatory drug testing, increased sentences for positive drugs test, and searches for drug possession (HM Prison and Probation Service, 2018; Ministry of Justice, 2018, 2019a). There is much less emphasis by government on inappropriate and unsafe prescribing of psychoactive medications that can be misused or diverted, despite concern from the Prison and Probation Ombudsman (Moody, 2019).

Any prescribed medication has the potential to be misused and cause harm. The Royal College of General Practitioners (RCGP) 2019 guidance Safer Prescribing in Prisons highlights that drugs with psychoactive effects have the highest risk of misuse, diversion, and dependence and that they should not be prescribed unless absolutely necessary (See supporting information - File 1) (Bicknell, Farmer, \& Watson, 2019). Psychotropic medications are designed to have a psychological effect. Their prescription is four times higher for men in prison than in the general population, and invalid prescriptions based upon British National Formulary indication are common (Hassan et al., 2016). This does not take into account the strength of evidence for a diagnostic indication for the medication in the first place. No data exist for the rates of prescribing for all psychoactive medications, including those that may be 
used in combination with other medications to achieve a psychological effect, for example tramadol, a pain killer.

Many male prisoners are polydrug users; in $2017 / 18$ 20.4\% of all random mandatory drug tests in prisons were positive, most commonly for novel psychoactive substances (NPS) (60\%), followed by cannabis, opiates, buprenorphine, and benzodiazepines (Ministry of Justice, 2018). Taking psychoactive medications in combination with illicit drugs may offer temporary relief from prison life but carries a risk of overdose and death (Poole, Bailey, \& Robinson, 2019). Psychoactive medication is a tradable commodity; their distribution is associated with intimidation, bullying, violence, and debt (Bicknell et al., 2019).

National Institute of Health and Care Excellence and RCGP guidance highlight the importance of medicines optimisation on reception and during stays in prison in order to mitigate the risk of adverse events (Bicknell et al., 2019; National Institute for Health and Care Excellence, 2015, 2016). Although medicines optimisation should follow a multidisciplinary team approach, prescribers (usually a general medical practitioner/primary care physician working mainly or exclusively in prisons) have an individual responsibility to assess the appropriateness (justifiable diagnostic indication for the medication) and safety (risk of overdose and death) of medications. Minimal guidance exists on how clinicians should achieve this over time. Inappropriate and unsafe prescribing of psychoactive medications is not confined to prisons. Our group has suggested that transparent medicines management in prisons could offer better healthcare than is available in the community (Poole et al., 2019).

We describe an evaluation of the medicines optimisation framework for psychoactive drugs that was implemented from the opening of HMP Berwyn, Wrexham, North Wales in February 2017. During the study period, all receptions were sentenced men transferred from other 
prisons. Our aim was to describe the extent of prescribing of concern for patients who had already been through reception medical processes in institutions where there was no structured programme to reduce it and preliminary outcomes of the medicines optimisation framework introduced.

\section{Methods}

\subsection{Ethical considerations}

As this study uses an anonymised routinely collected dataset, the Betsi Cadwaldr University Health Board NHS research and development department recommend that the project is exempt from ethics approval. This project is registered with the Betsi Cadwaldr University Health Board Clinical Audit and Effectiveness office.

\subsection{Context}

The prison opened in February 2017. It is the largest in the UK and second largest in Europe, designed to hold up to 2106 category C male prisoners (HM Prison and Probation Service, 2020). Category C prisoners are defined as "prisoners who cannot be trusted in open conditions but who do not have the resources and will to make a determined escape attempt" (Ministry of Justice, 2011). The stated aim for the prison is to foster a culture of empowerment and respect (HM Prison and Probation Service, 2020). By the end of March 2019, it held a total of 1283 men (Ministry of Justice, 2019b). Health services are provided by Betsi Cadwaladr University Health Board. Two general practitioners (GPs) provide primary care services and developed the medicines optimisation framework (MOF). This framework was initiated in collaboration with pharmacy services, substance misuse services, and with the 
support of prison management when the prison first started to receive men. In this paper we report outcomes of the first 21 months of implementation.

\subsection{Intervention}

\section{(i) At reception}

On reception, repeat prescriptions are checked by a nurse for any drug with psychoactive effects (See supporting information - File 2). When such prior prescription is reported, the man is asked to provide urine for a drug screening test and the result is made available on the electronic health record. This includes primary care records (community and prison) and prison transfer records. The whole electronic health record is reviewed on the same day by a GP. Appropriateness of a medication is assessed by thorough scrutiny of the records to look for the diagnostic criteria which would legitimise use of a particular medication. Safety of a medication is assessed by reviewing alerts for intoxication recorded by health professionals at the previous prison, for example, suspected use of novel psychoactive substances. There are a number of possible outcomes from this review (Table 1, Figure 1):

- Where medication is appropriate and there are no safety concerns, the prescription is continued. Medication, including controlled drugs, will be 'in possession' by default, meaning that each man will hold 28 days' supply of his own medication in his cell, unless there are written instructions to the contrary. An 'in possession risk assessment template' is completed for each patient and then signed off by a senior pharmacist (Supporting information - File 3). This ensures that the patient is able to take the medication at the correct time as pharmacy dispensing times may not fit for certain drugs, for example, therapeutically justifiable hypnotics, and maintains patient autonomy. There are unannounced medication counts to check for stockpiling. 
- Where there is no justifiable diagnostic indication for the medication ('inappropriate medication'), it is not prescribed. A GP appointment is made for the next morning where further history, examination, and investigations are completed as necessary. If the medication is still deemed inappropriate, the reasons for discontinuation are discussed with the patient. A reducing regime is prescribed for drugs where withdrawal symptoms are likely. If the patient does not agree, discontinuation proceeds regardless.

- Where a prescription for a sedative drug appears appropriate but there are safety concerns, it is not prescribed. An appointment is made for the next day to assess (history taking, examination, and investigation) to determine whether continuation is in the patient's best interest. Where the prescription is considered appropriate despite safety concerns, and there is no non-psychoactive alternative, the medication is dispensed by staff-observed single dosing ('not in possession').

- The medications of all patients with a psychiatric diagnosis are reviewed by a prison based psychiatrist within a week. The psychiatrist will scrutinise prison and community records, order appropriate investigations (for example, electrocardiogram [ECG] for some anti-psychotic drugs), and a face to face review will be completed within 6 weeks. For these patients, medication is continued but 'not in possession' prior to psychiatric review.

\section{(ii) Follow up}

In cases where there was an appropriateness concern at reception (for example, further investigation of diagnosis needed), the patient will have a GP follow up appointment within 2 weeks. Information that might raise a safety concern is shared with the GP via the electronic system, allowing them to re-evaluate the medication risk. Circumstances that would lead to an urgent clinical review include: 
- $\quad$ Failure of a random mandatory drug test

- $\quad$ Report of a patient found intoxicated

- Incorrect count of 'in possession' medication

- $\quad$ Positive urine drug screen from substance misuse services

\subsection{Service evaluation measures}

One of us (JL), who is a GP, searched the clinical database for men who had a urine drug screen between February 2017 and November2018. The clinical notes and results were reviewed to identify those who had one at reception solely as part of the Medicines Optimisation Framework. Basic demographic information including age and date of reception was collected. Changes to psychoactive medications at reception or on review were evaluated and attributed to appropriateness concerns, safety concerns, or both based upon of principles of good practice in prescribing (General Medical Council, 2013; National Institute for Health and Care Excellence, 2015).

\subsection{Analyses}

All data were transcribed into an Excel spreadsheet by JL. Data were checked by EB. Any inconsistencies in data were reported back to $\mathrm{JL}$ for review and amendment from the original electronic notes. After the data checking process there were no missing data. We undertook univariate linear regression analysis of the proportion of positive and negative urine drug screens per month from March 2017 to October 2018. February 2017 and November 2018 data were excluded from this analysis due to incomplete data collection. The number of medication changes made at reception and follow up were analysed using Fisher's exact test 
(two-tailed). All statistical calculations were performed using GraphPad Prism version 5 for Windows. Revised Standards for Quality Improvement Reporting Excellence (SQUIRE 2.0) were used to help write the manuscript (Ogrinc et al., 2016).

\section{Results}

\subsection{Database search}

1941 men arrived at the prison during the study period (Supporting information - File 4). No man was registered more than once. Seven hundred and ninety-five $(41 \%)$ had a urine drug screen, most of these $(634 / 795,80 \%)$ solely because of the medicines optimisation framework. The median age of men on a prescribed psychoactive medication was 37.0 years (inter-quartile range [IQR] 31-44).

\subsection{Reception process}

Of 634 men asked for a urine sample for screening under the framework, ten refused to provide a sample. One hundred and sixty-six (26\%) had a positive result for an illicit substance that was not accounted for by their prescription. Twenty-six (4\%) had a negative urine drug screen for a medication that they were prescribed, suggesting diversion of the drug.

There was a concern that men would obtain 'clean' urine as information about reception processes spread. We tested for this by completing linear regression analysis on screening results that had been completed at reception as part of the framework. There was an increasing trend in the proportion of tests that were negative for illicit substances and a decreasing trend in the proportion of tests that were positive for illicit substances (Supporting information - File 5). This was a weak trend $\left(R^{2}=0.1821\right.$, and $R^{2}=0.1749$, respectively), and 
neither line was significantly different from zero $(P=0.0665$ and $P=0.0606$, respectively), meaning that there is minimal statistical evidence to support the possibility that men were manipulating the system on arrival.

Transfer records of 154 (24\%) of the 634 urine screened men showed novel psychoactive substance use in the 3 months prior to the test. We found that, although evidence of intoxication was available in the notes, it had generally not been acted upon at the patient's previous institution. Of those with evidence of using novel psychoactive substances, 41 had a positive urine drug screen at reception and one man refused this screen.

Two hundred and ninety-five (46.5\%) of the urine screened men had their psychoactive medication prescription changed at reception; the commonest reason for change was the combination of appropriateness and safety concerns (Table 2).

\subsection{Follow up}

Three hundred and fifty-six (56\%) of the 634 men in the medicines optimisation framework had no follow up interventions after the initial reception process (Table 2). Reasons for this included the patient having an appropriate prescription with no subsequent safety concerns, or the patient leaving prison prior to follow up. Every patient has at least two medication reviews per year.

Over $40 \%(278,44 \%)$ of the men in the framework did have a follow up intervention and all but three required changes to their prescription (Table 2). Appropriateness concerns were addressed through face-to-face medication review. Of those requiring a face-to-face review, 112 (41\% of 272 recorded) had a medication change (Table 3). Safety concerns leading to a review were provoked by intoxication, incorrect medication count, or positive urine drug 
screen. Medication changes on safety grounds were made for 106 (39\% of 270 recorded), 84 (32\% of 263 ) and 31 ( $12 \%$ of 266 ) in respective groups (Table 3 ). Medication changes at follow up were more likely in those men who had had no medication change at reception. Of the 339 men who had no change to their psychoactive medication at reception, 179 (53\%) required changes at follow up due to safety concerns, appropriateness concerns, or both. Of the 295 on psychoactive medication at reception whose prescription was changed, just 96 (32.5\%) had a further change during the study period $(P<0.0001)$.

Overall, including reception and follow up (follow up period dictated by patient either leaving the prison or the study ending), three-quarters of the men (474 of $634,75 \%$ ) had a psychoactive medication change due to appropriateness or safety concerns during the 21 months of the study (Table 2). Indirect evidence of the success of the medicines optimisation framework was highlighted in a recent independent inspection of the prison where it was noted that 'very few prisoners were prescribed tradeable medicines' (HM Inspectorate of Prisons, 2019).

\section{Discussion}

About one third of all men arriving at HMP Berwyn were on psychoactive medication at the time of arrival. All had been transferred from other prisons. In almost half of these cases, the prescription was deemed inappropriate, unsafe, or both inappropriate and unsafe. This high proportion of prescriptions that needed to be changed is of concern given probable earlier opportunities to review medication. It is thus likely that appropriateness and safety of prescriptions for psychoactive drugs are not being considered adequately across the prison estate. It is recognised that prison prescribers may 'inherit' prescriptions commenced in the 
community, that there are risks in not continuing some prescription and thus re-evaluation of need for them takes time. Further, withdrawal of a drug to which a prisoner feels attached or on which he is dependent is a significant task in itself. Nevertheless, another factor may be that the risk of harm arising from abuse of psychoactive medications (particularly for people with substance misuse histories) may be less apparent to doctors unfamiliar with prison environments (Bicknell, 2013). Prescribers working in prison should have training to provide them with skills to manage these risks appropriately. There is a precedent for this with opiate substitution programmes (Wright, French, \& Allgar, 2014). Our prison GPs reported that they benefited from specialist training in substance misuse. All systems are open to manipulation, but we found no statistical evidence to suggest that men were using 'clean' urine on arrival. This must be monitored as it is a key point where the medicines optimisation framework could be exploited.

A nationwide study evaluating psychotropic medication use (including hypnotics, anxiolytics, antipsychotics, antidepressants, and CNS stimulants) in prison found that $35 \%$ of prescriptions had no accompanying record of an indication supported in the British National Formulary (Hassan et al., 2016). It is likely this is an underestimate of inappropriate prescribing as it does not include any scrutiny of the methods used to assess the strength of the evidence used to make the diagnosis and justify the medication, nor does it include all psychoactive medications. We found that about half of Berwyn's men were on a psychoactive medication for a diagnosis without evidence of a disorder justifying the use of this medication, or a nonessential medication that they were not taking.

Perhaps one of the most important findings is the need for continuing risk evaluation after the reception process. Even in Berwyn, where there was high awareness of the risks and 
formal adoption of the medicines optimisation framework, there were many men who had no prescription changes at reception but needed them later. The prescription and taking of prescribed medication is a dynamic process and the task never complete. Having the framework helped identify any problems, such as evidence of intoxication, very quickly.

Poly-drug misuse was common. Psychoactive prescription drugs interact with illicit drugs, increasing the risk of death. Novel psychoactive substances are particularly problematic because they are more difficult to detect, for example, they have no characteristic smell when smoked (Ministry of Justice, 2018; Ralphs, Williams, Askew, \& Norton, 2017). Drugs known as synthetic cannabinoids can be addictive and ultra-potent. Unlike natural cannabis, their use has been implicated in drug related deaths in prisons (Moody, 2019; Ralphs et al., 2017). This underlines the need for clinicians to be aware of their possible use when assessing the safety of prescribing a psychoactive medication that is otherwise appropriately indicated.

Control of access to potentially hazardous prescription drugs is an important element in prison substance misuse strategies, so prison doctors have a particularly important role in containing this. In principle, the situation in the community is no different. Clinicians working in all areas of healthcare should take ownership of the problem and its solutions. Patients may react negatively to having their medication stopped, but the primary objective is to promote health. The prescriber must act in the patient's best interest, which sometimes means saying "no". This applies to all fields of medicine (Poole et al., 2019).

A strength of this study is that is describes and evaluates implementation of a medicines optimisation framework for psychoactive medications. Bodies such as National Institute for Health and Care Excellence and RCGP have set out principles of how to avoid drug related morbidity and mortality (Bicknell et al., 2019; National Institute for Health and Care 
Excellence, 2016) but, to the best of our knowledge, this is the first study to describe implementation of these principles.

An essential element of this framework is that it is multidisciplinary, using expertise from GPs, pharmacists, substance misuse services, and psychiatrists, all of whom have had extensive experience in secure environments, as recommended by the Royal Pharmaceutical Society and others (Choudhry \& Evans, 2014; Royal Pharmaceutical Society, 2017).

Some limitations of this study must be considered. First, data were gathered retrospectively from the electronic notes by a single person (JL). Data were cleaned by a second person (EB) to identify inconsistencies to try to reduce the risk of transcription errors. It was not practical to have dual person data entry due to constraints on time and access to the prison database. Secondly, data collection was completed by one of the GPs delivering the intervention (JL). It is normal NHS practice for clinicians involved in service provision also to be involved in routine data collection for service evaluation, but does not allow for fully independent data collection. Thirdly, when considering the wider implications for prescribing in prisons we should bear in mind that the cohort studied at HMP Berwyn is not representative of the prison population as a whole. This population did not include any remand (pre-trial or pre-sentence) prisoners or those from establishments with lower levels of security, where psychoactive medication prescribing and those with substance misuse problems form a larger subsection of the population.

Fourthly, information about the type of medication was not included in this routinely collected data set. The aim of the project was to evaluate the application of a set of principles to all medications with a psychoactive profile rather than to collect information about the 
medications themselves, but we have included the list of medications classed as psychoactive for the purposes of evaluating the framework (Supporting information - file 2), and provided examples of appropriateness and safety concerns (Table 1).

Fifthly, it was beyond the scope of this project to collect data about longer term impacts of the medicine optimisation framework. Anecdotally, at HMP Berwyn, it changes behaviour and encourages prisoners to take responsibility for their own health, both of which are key factors in mitigating institutionalisation. Also, it is likely to have a multifaceted health economic impact, through absolute reduction in number of prescribed items, reduced pressure on pharmacy and nursing teams, reduced pressure on security and fewer health crises. These are balanced by costs in staff times, disruption when men have medication discontinued, and potential complaints. We plan future research to answer some of these questions.

If medicines optimisation frameworks are to be implemented across the whole prison estate, there must be greater recognition and support from HM Prison and Probation Service about the role of inappropriate and unsafe prescription medications in contributing to the supply and misuse of drugs in prison. Appropriately modified, a similar framework might help reduce inappropriate and harmful prescribing in hospitals and in the community.

\section{Conclusions}

We have described and evaluated the implementation of a framework for optimisation of psychoactive medication prescribing based upon principles of good prescribing. Our findings underscore the need for this, given the high proportion of men receiving psychoactive medication inappropriately or at some risk to their safety, and show that implementation is feasible. The framework could be adopted across other prisons in England and Wales to contribute to minimising risk from drug use in prisons. Many of the same principles might be 
applied in wider clinical practice too, this also having a potential impact on prisoners as so many arrive on no longer appropriate prescriptions started in the wider community. Further research is required to understand the impact of such a framework on longer term health outcomes, including transitionary phases from prison back to the community. 


\section{References}

Bicknell, M. (2013). The pain of pregabalin prescribing in prisons. The British Journal of General Practice, 63(613), 405. https://doi.org/10.3399/BJGP13X670615

Bicknell, M., Farmer, D., \& Watson, C. (2019). Safer Prescribing in Prisons. Royal College of General Practitioners. Retrieved from https://www.rcgp.org.uk/policy/rcgp-policy-areas/prisonmedicine.aspx

Choudhry, K., \& Evans, N. (2014). Beyond equivalence of care in prison pharmacy. International Journal of Pharmacy Practice, 22(5), 363-365. https://doi.org/10.1111/ijpp.12089

General Medical Council. (2013). Good practice in prescribing and managing medicines and devices. Retrieved from https://www.gmc-uk.org/ethical-guidance/ethical-guidance-for-doctors/prescribingand-managing-medicines-and-devices

Hassan, L., Senior, J., Webb, R. T., Frisher, M., Tully, M. P., While, D., \& Shaw, J. J. (2016). Prevalence and appropriateness of psychotropic medication prescribing in a nationally representative crosssectional survey of male and female prisoners in England. BMC Psychiatry, 16(1). https://doi.org/10.1186/s12888-016-1055-7

HM Inspectorate of Prisons. (2019, July 11). HMP Berwyn. Retrieved from https://www.justiceinspectorates.gov.uk/hmiprisons/inspections/hmp-berwyn/

HM Prison and Probation Service. (2018, July 12). HM Prison and Probation Service Business Plan 2018 to 2019. Retrieved from https://www.gov.uk/government/publications/hmpps-business-plan2018-to-2019

HM Prison and Probation Service. (2019, April 3). National Prison Drugs Strategy. Retrieved from https://www.gov.uk/government/publications/national-prison-drugs-strategy

HM Prison and Probation Service. (2020, March 25). Berwyn prison information. Retrieved from: http://www.justice.gov.uk/contacts/prison-finder/berwyn-prison-information

Ministry of Justice. (2011, September 1) Prison Service Instructions 2011-40 Categorisation and Recategorisation of Adult Male Prisoners. Retrieved from

https://www.justice.gov.uk/offenders/psis/prison-service-instructions 2011

Ministry of Justice. (2018, July 26). HM Prison and Probation Service Annual Digest: 2017 to 2018. In Ministry of Justice. Retrieved from https://www.gov.uk/government/statistics/annual-hm-prisonand-probation-service-digest-2017-to-2018

Ministry of Justice. (2019a). 10 Prisons Project sees drops in violence and drugs. Retrieved from https://www.gov.uk/government/news/10-prisons-project-sees-drops-in-violence-and-drugs

Ministry of Justice. (2019b). Prison Population Figures: 2019 - Population bulletin: monthly March 2019. Retrieved from https://www.gov.uk/government/statistics/prison-population-figures-2019

Moody, E. (2019, January 28). The worrying increase of drug-related deaths in custody. Retrieved from Prisons and Probation Ombudsman website: https://www.ppo.gov.uk/blog/the-worryingincrease-of-drug-related-deaths-in-custody/ 
National Institute for Health and Care Excellence. (2015, March 4). Medicines optimisation: the safe and effective use of medicines to enable the best possible outcomes. Retrieved from NICE website: https://www.nice.org.uk/guidance/ng5/chapter/1-Recommendations

National Institute for Health and Care Excellence. (2016, November 2). Physical health of people in prison. Retrieved from NICE website: https://www.nice.org.uk/guidance/ng57

Ogrinc, G., Davies, L., Goodman, D., Batalden, P., Davidoff, F., \& Stevens, D. (2016). SQUIRE 2.0 (Standards for QUality Improvement Reporting Excellence): revised publication guidelines from a detailed consensus process. BMJ Quality \& Safety, 25(12), 986-992. https://doi.org/10.1136/bmjqs2015-004411

Poole, R., Bailey, J., \& Robinson, C. A. (2019). The opioid crisis and British prisons. Criminal Behaviour and Mental Health, cbm.2136. https://doi.org/10.1002/cbm.2136

Ralphs, R., Williams, L., Askew, R., \& Norton, A. (2017). Adding Spice to the Porridge: The development of a synthetic cannabinoid market in an English prison. International Journal of Drug Policy, 40, 57-69. https://doi.org/10.1016/J.DRUGPO.2016.10.003

Royal Pharmaceutical Society. (2017, February). Professional Standards for optimising medicines for people in secure environments. Retrieved from https://www.rpharms.com/Portals/0/RPS document library/Open access/Professional standards/Optimising medicines in secure environments/Professional Standards Secure Environments-edition-2.pdf?ver=2017-05-18-112406223

Wright, N. M., French, C., \& Allgar, V. (2014). The safe implementation of a prison-based methadone maintenance programme: 7 year time-series analysis of primary care prescribing data. BMC Family Practice, 15(1), 64. https://doi.org/10.1186/1471-2296-15-64 


\begin{tabular}{|l|l|}
\hline \multirow{3}{*}{$\begin{array}{c}\text { Appropriateness } \\
\text { concerns }\end{array}$} & $\begin{array}{l}\text { Examples } \\
\text { recognised guidelines) to justify prescription }\end{array}$ \\
\cline { 2 - 3 } & $\begin{array}{l}\text { Urine drug screen negative for prescribed } \\
\text { medication suggesting it is not being taken }\end{array}$ \\
\hline \multirow{7}{*}{ Safety concerns } & Evidence of intoxication (e.g. NPS or alcohol) \\
\cline { 2 - 3 } & Evidence of illicit substance misuse \\
\cline { 2 - 2 } & $\begin{array}{l}\text { Incorrect medication count suggesting diversion } \\
\text { of medications or stockpiling }\end{array}$ \\
\cline { 2 - 2 } & $\begin{array}{l}\text { Urine drug screen showing positive substances } \\
\text { which are not prescribed }\end{array}$ \\
\cline { 2 - 2 } & Drug seeking behaviour \\
\cline { 2 - 2 } & Recent use of NPS \\
\cline { 2 - 2 } & $\begin{array}{l}\text { Methadone dose too low for level of opiate } \\
\text { tolerance evidenced by the presence of } \\
\text { objective withdrawal }\end{array}$ \\
\cline { 2 - 2 } & $\begin{array}{l}\text { Methadone dose too high for level of opiate } \\
\text { tolerance evidenced by acute intoxication }\end{array}$ \\
\hline
\end{tabular}

Table 1. Examples of appropriateness and safety concerns. 


\begin{tabular}{|c|c|c|c|}
\hline & & \multicolumn{2}{|c|}{ Safe to prescribe } \\
\hline & & Yes & No \\
\hline \multirow{2}{*}{ 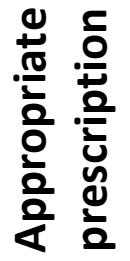 } & Yes & Continue & Stop \\
\hline & No & Stop & Stop \\
\hline
\end{tabular}

Figure 1. Decision matrix for prescription of a psychoactive medication based upon appropriateness and safety. 


\begin{tabular}{|l|r|}
\hline \multicolumn{2}{|c|}{ Medication changed at reception } \\
\hline Reason & \multicolumn{1}{c|}{$\mathbf{n}$} \\
\hline Appropriateness and safety & $194(30.6 \%)$ \\
\hline Appropriateness only & $56(8.8 \%)$ \\
\hline Safety only & $45(7.1 \%)$ \\
\hline No change & $339(53.5 \%)$ \\
\hline \multicolumn{2}{|c|}{ Medication changed at follow up } \\
\hline Reason & $\mathbf{n}$ \\
\hline Appropriateness and safety & $43(6.8 \%)$ \\
\hline Appropriateness only & $69(10.9 \%)$ \\
\hline Safety only & $163(25.7 \%)$ \\
\hline No change & $3(0.5 \%)$ \\
\hline No follow up required & $356(56.2 \%)$ \\
\hline \multicolumn{2}{|c|}{ Medication change overall } \\
\hline Reason & $\mathbf{n}$ \\
\hline Appropriateness and safety & $234(36.9 \%)$ \\
\hline Appropriateness only & $81(12.8 \%)$ \\
\hline Safety only & $159(25.1 \%)$ \\
\hline No change & $160(25.2 \%)$ \\
\hline
\end{tabular}

Table 2. Reason for medication change at reception, at follow up, and overall. 


\section{Appropriateness concerns}

\begin{tabular}{|c|c|c|}
\hline \multirow[t]{3}{*}{ Face to face medication review } & Medication change & $112(41.2 \%)$ \\
\hline & No medication change & $160(58.8 \%)$ \\
\hline & Total & 272 \\
\hline \multicolumn{3}{|c|}{ Safety concerns } \\
\hline \multirow[t]{3}{*}{ Evidence of intoxication } & Medication change & 106 (39.3\%) \\
\hline & No medication change & $164(60.7 \%)$ \\
\hline & Total & 270 \\
\hline \multirow[t]{3}{*}{ Medication count incorrect } & Medication change & $84(31.9 \%)$ \\
\hline & No medication change & $179(68.1 \%)$ \\
\hline & Total & 263 \\
\hline \multirow[t]{3}{*}{ Subsequent urine drug screen } & Medication change & $31(11.7 \%)$ \\
\hline & No medication change & 235 (88.3\%) \\
\hline & Total & 266 \\
\hline
\end{tabular}

Table 3. Medication changes at follow up. 
Supplementary file 1

Medications with psychoactive effects at high risk of misuse, diversion, and dependence. Information collated from Royal College of General Practitioners 'Safer Prescribing in Prisons' guidance. (Bicknell, Farmer, \& Watson, 2019)

\begin{tabular}{|l|l|}
\hline \multicolumn{1}{|c|}{ Class of medication } & \multicolumn{1}{c|}{ Example } \\
\hline Sedating antidepressants & Mirtazapine \\
\hline Antipsychotics & Quetiapine \\
\hline Opiods & Tramadol \\
\hline Gabapentinoids & Pregabalin \\
\hline Hypnotics & Zopiclone \\
\hline Anxiolytics & Diazepam \\
\hline Certain Antiepileptics & Clonazepam \\
\hline
\end{tabular}




\section{Supplementary file 2}

Prescription medicines that indicate the need for a urine drug screen on arrival at HMP Berwyn

Acamprosate; Alprazolam; Amisulpiride; Amitriptyline; Aripiprazole; Atomoxetine; Baclofen; Buprenorphine; Bupropion; Buspirone; Carbamazepine; Chlordiazepoxide; Chlorphenamine; Chlorpromazine; Citalopram; Clobazam; Clomipramine; Clonazepam; Clozapine; Cocododamol; Codeine; Co-dydramol; Cyclizine; Dexamfetamine; Diamorphine; Diazepam; Dihydrocodeine; Diphenhydramine; Disulfiram; Domperidone; Dosulepin; Duloxetine; Ethosuximide; Fentanyl; Flupentixol; Fluphenazine; Gabapentin; Haloperidol; Hydromorphone; Hydroxyzine; Hyoscine; Imipramine; Lacosomide; Lamotrigine; Levetiracetam; Levomepromazine; Lisdexamfetamine; Lithium; Lofexedine; Loperamide; Lorazepam; Melatonin; Methadone; Methylphenidate; Metoclopramide; Midazoplam; Mirtazapine; Modafanil; Morphine; Naltrexone; Nefopam; Nitrazepam; Nortriptyline; Olanzapine; Ondansetron; Oxazepam; Oxycodone; Paloperidone; Paroxetine; Perampenel; Pethidine; Phenelzine; Phenobarbital; Phenytoin; Pholcodine; Pregabalin; Prochlorperazine; Promazine; Promethazine; Pseudoephedrine; Quetiapine; Reboxetine; Risperidone; Rizatriptan; Sertraline; Sodium valproate; Sulpiride; Tapentadol; Temazepam; Topimirate; Tramadol; Trazadone; Valproic acid; Zolpidem; Zonisamide; Zopiclone; Zuclopenthixol.

Total - 97 medications 


\section{Supplementary file 3}

Information included in 'In possession risk assessment template' on HMP Berwyn electronic patient record system:

Patient

- Name

- Address

- Telephone

- Mobile telephone

- Client ID

- Date of birth

Completed by:

- Name

- Date

In possession risk assessment questionnaire and actions: (answer High/ Medium/ Low)

1. Physical Health - Does the patient have the understanding of health problems likely to result in failure to take medication?

2. Physical Health - Is the patient on a medication posing a significant and/or immediate risk if medication is omitted?

3. Mental Health - Does the patient have capacity/ learning difficulties, problems reading, or any language issues?

4. Mental Health - Does the patient have depression or risk of self harm or an open Assessment, Care in Custody and Teamwork (ACCT) plan?

5. Mental Health - Does the patient have psychosis indicating a compliance risk?

6. Security/ Safety - Has or is the patient demonstrating drug seeking behaviour?

7. Security/ Safety - Has the patient had a positive mandatory drug test (MDT)?

8. Security/ Safety - Has the patient tested positive for illicit substances?

9. Security/ Safety - Does the patient have a history of trading medication or incorrect room in possession medication check ups?

Action for prescriber:

- Low physical or mental health risk - in possession medication for 28 days and repeat template for 6 issues

- Medium physical or mental health risk - Not in possession for 28 days and request an appointment within that time period to reassess in possession status of patient

- High physical or mental health risk - Not in possession for 28 days and repeat for 3 issues 
- High security risk - In possession (7 or 28 days) and room medication check ups (send task to admin) and appointment in medication review clinic (send task) and urine toxicology 


\section{Supplementary file 4}

Flow diagram showing the process of identifying men with a prescription for a psychoactive medication on entering HMP Berwyn during the study period February 2017 - November 2018. $n$ - number of patients.

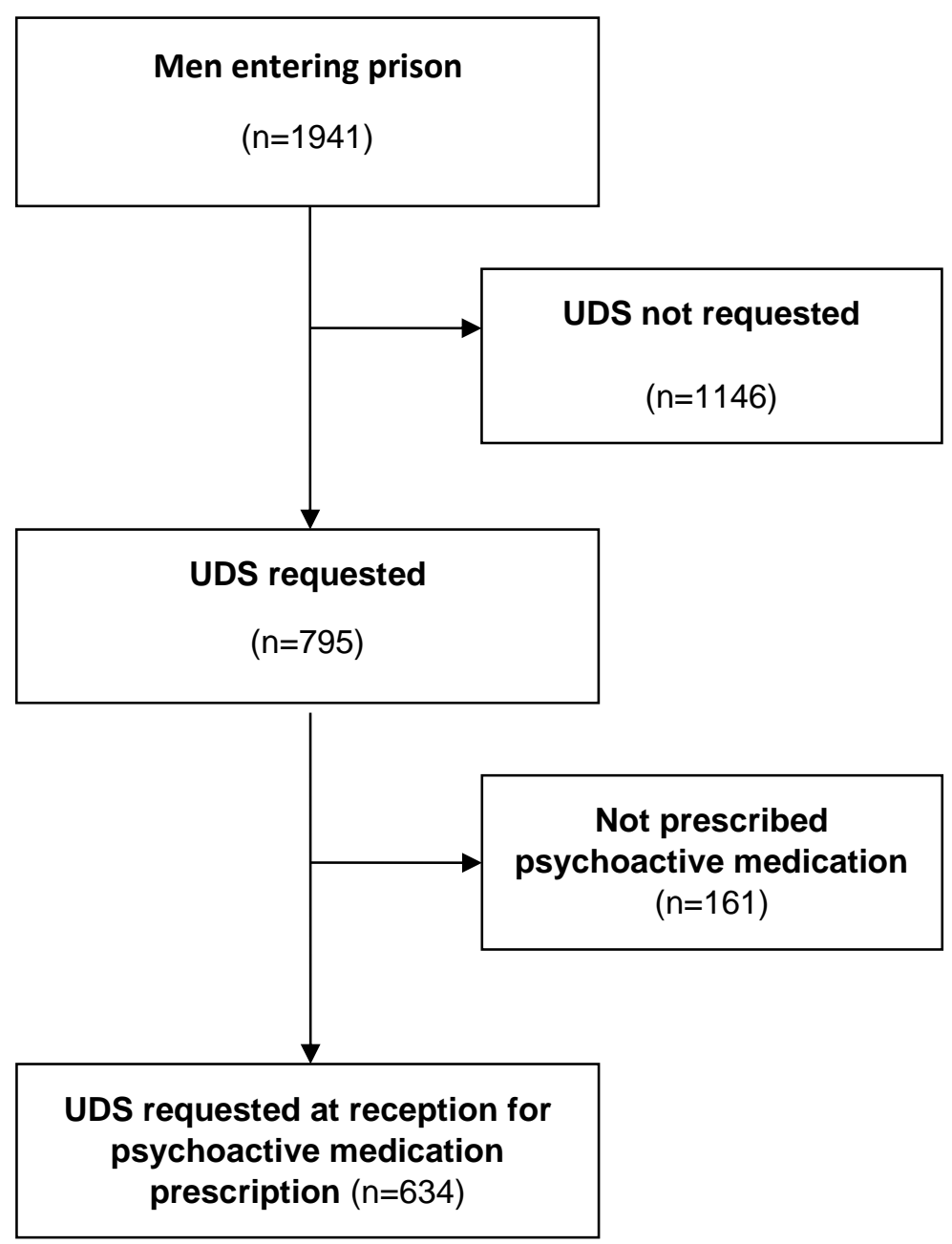




\section{Supplementary file 5}

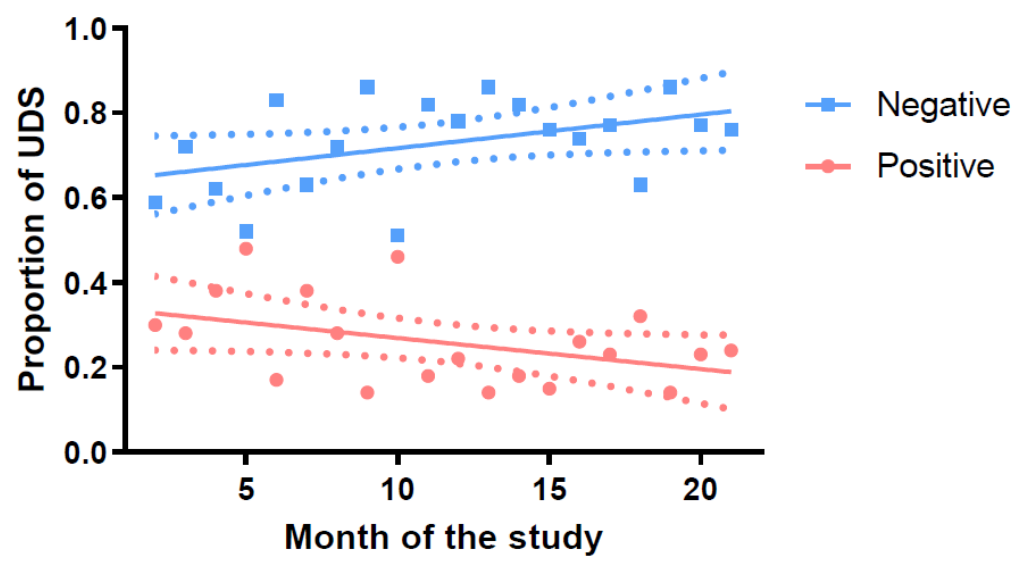

Proportion of positive (red) and negative (blue) UDS results per month. UDS results relate to those requested at reception for the MOF. Solid lines represent the means, and dotted lines the $95 \%$ confidence intervals of linear regression analysis performed on the data. Month 1 (February 2017) and month 22 (November 2018) excluded as incomplete data collection for those months. UDSurine drug screen. MOF - medicines optimisation framework. 